
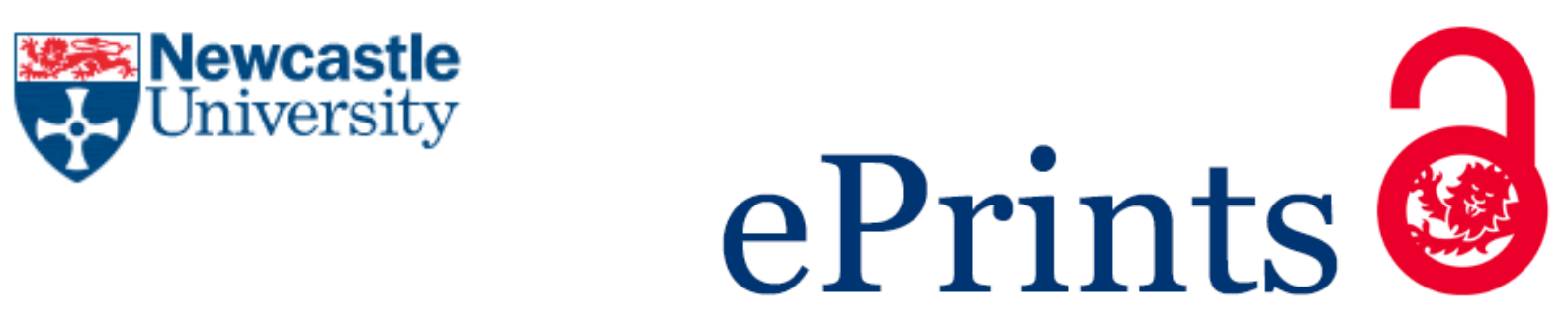

\author{
Kelsey D. (2018) \\ Journalism and critical discourse studies.
}

In: Richardson, J. and Flowerdew, J. (eds.) The Routledge Handbook of Critical Discourse Studies.

Abingdon: Routledge.

\title{
Copyright:
}

This is an Accepted Manuscript of a book chapter published by Routledge in The Routledge Handbook of Critical Discourse Studies on 06/07/2017, available online:

https://www.routledge.com/The-Routledge-Handbook-of-Critical-Discourse-Studies/Flowerdew-

Richardson/p/book/9781138826403.

Date deposited:

$19 / 07 / 2017$

Embargo release date:

06 January 2019 


\section{JOURNALISM AND CRITICAL DISCOURSE STUDIES}

\section{Introduction}

This chapter accounts for three developmental stages of qualitative approaches to CDA in journalism studies. It starts with approaches to Critical Linguistics (CL), which began to account for the social production of language in news texts (Fowler et al, 1979; Trew, 1979; Kress, 1983; Fowler, 1991; Bell, 1991; Hodge and Kress, 1993). It then covers a second development where CL frameworks informed expansive models of Critical Discourse Analysis (CDA) that were designed to rigorously interrogate journalistic texts, discursive practices and social contexts (van Dijk, 1988, 1991; Richardson, 2007; Kelsey, 2015c). This second stage also accounts for the transnational developments that have occurred across the field of critical discourse studies. The third section accounts for more recent developments in CDA that have expanded beyond linguistic analysis through multimodal approaches (Machin and Mayr, 2012; van Leeuven and Kress, 2011) to news media and, more recently, online news (Kelsey, 2015a; Bednarek and Caple, 2012; Caple, 2013; Knox, 2007, 2010). There are many bodies of literature beyond the scope of this chapter - especially in the significant and highly respected quantitative (corpus) approaches that have been developed for large-scale studies on the language of journalistic content (Baker and McEnery, 2015; Baker, et al. 2008; Gabrielatos and Baker, 2008). But this chapter shows readers how CDA and journalism studies have developed over time through a particular direction and design that is sensitive to the social production and ideological operations of news discourse. It demonstrates what CDA needs to do in order to continually progress and account for the rapid developments of multimedia platforms and online journalism.

\section{Language, ideology and critical linguistics}

$\mathrm{CL}$ provided the foundations of linguistic frameworks designed to critically interrogate journalistic material in relation to power and society (Fowler et al, 1979; Trew, 1979; Kress, 1983; Chilton, 1985; Fowler, 1979; 1991; Hodge and Kress, 1993). With its connections to Halliday's (1978) Systemic Functional Linguistics, CL's focus on grammar and ideology provided an ideal framework for analysing language in political environments and critical contexts, such as newspapers. In Language and Control (1979) Fowler et al.'s seminal work developed CL through its micro analytical techniques in relation to more macro orientated contexts such a class structure and social power, which were significant to journalism studies. This work laid the foundations for expansive $\mathrm{CL}$ research on media texts that would provide the roots to CDA. Amongst various innovations, Trew's (1979) work on linguistic variation and ideology in newspaper discourse became a milestone text that paved the way for CL's introduction in critical media research. He showed how various linguistic mechanisms such as nominalization and passivization, which later became familiar analytical traits in CDA, functioned in news stories. In doing so, Trew developed "systematic ways of isolating ideology in discourse to illustrate further aspects of the linguistic expression of the relations of newspapers and ideologies to social processes" (1979:118). For example, Trew's work on press coverage of the 1977 Notting Hill Carnival (1979) showed how print news covered social violence through different language choices across texts that reflect the ideological interests of particular news sources, according to their accounts of social groups and their agency.

Most importantly, whilst this work showed how $\mathrm{CL}$ could be applied in journalism studies, this was only on the condition that the frameworks applied could understand the specific generic context and cultural landscape of the press. As a former journalist, Bell's (1991) work adopted this ethos. Bell was particularly astute in the insights he brought to $\mathrm{CL}$ : his ability to introduce practical and environmental 
analysis of news production shed light on how language is a product of explicit functional processes of the newsroom. Bell's work covered a range of practical journalistic factors such as the production of a news story that determined its structure and narrative. His experience meant he could account for the newsgathering processes of a newsroom and explain the values behind processes of news storytelling.

For media scholars adopting innovative but complex frameworks of CL theory in journalism studies, Fowler (1991) also provided an accessible approach. Fowler addressed the micro structures of language and power through to the macro ideological contexts of newspapers and their editorial values. He argued that the news media often reproduce the dominant order due to the ideological influence of those in positions of power. Powerful institutions "provide the newspapers with modes of discourse which already encode the attitudes of a powerful elite. Newspapers in part adopt this language for their own and ... reproduce the attitudes of the powerful" (Fowler, 1991: 23-24). Fowler provided a series of case studies including: linguistic formations in discriminatory discourses of gender and power between social groups; discursive constructions of public opinion and consensus in newspapers; and the argumentative generic conventions and forms of modality that newspaper editorials adopt in their style of 'connecting' with readers. Fowler argued that language is always produced by sources with their own ideological interests: "Anything that is said or written about the world is articulated from a particular ideological position: language is not a clear window but a refracting, structuring medium" (1991:10).

Fowler's approach was a welcome effort to explicitly address interdisciplinary nuances (through connections to media studies) that valued the work of critical media research (Philo et al., 1982), but was also committed to a more sophisticated understanding of language in media texts:

The 'standard position' of current students of the media is that news is a construct which is to be understood in social and semiotic terms; and everyone acknowledges the importance of language in this process of construction. But in practice, language gets relatively meagre treatment, when it comes to analysis: the Glasgow Group, and Hartley, for example, are more interested in, and better equipped technically to analyse, visual techniques in television (ibid: 8)

By Fowler's admission, there are multiple dimensions and discursive components in the construction of any newspaper text that are beyond the scope of CL. The layout, images, headlines, typography and other interactive elements of newspapers are not considered in his analysis. Particularly in the world of online news, stories are constructed through unique and complex textual and digitally interactive layouts that require multimodal frameworks to analyse them in their entirety (Bendarek and Caple, 2012; Knox, 2007, 2010). But Fowler was justifiably content in his focus on language from a CL perspective through a framework designed to do a specific job: interrogate the social and ideological role of language in the news. He acknowledged the importance of understanding contextual circumstances and processes of production behind news discourse, which his peers such as Bell (1991) had demonstrated the significance of. Subsequently, developments in CDA since CL have sought to further address the practical and contextual complexities of news content beyond exclusive analyses of language.

\section{Critical discourse analysis and journalism studies}

A significant development from CL to CDA came in the work of van Dijk (1988a, 1988b, 1991, 1998). This work presented a new, interdisciplinary approach to critical media analysis through a framework 
of discourse analysis and social cognition. Van Dijk differentiated this approach from other critical media and communication research: "We ... find that few approaches pay sufficient attention to the study of news as discourse in its own right. This is particularly true of the macrosociological approaches to news. We also believe that the cognitive dimension of news production and understanding has been neglected" (1988a: 2-3). From a discourse analytical grounding, van Dijk has always argued that news should be studied in its relevant context but still as a significant form of public discourse. He understood that mass communication research was already concerned with the economic, social, and cultural contexts of news media, but he also stressed the importance of conducting structural analysis of news stories as a "qualitative alternative to traditional methods of content analysis" (1988:vii). He claimed that news discourse was "explicitly linked to social practices and ideologies of newsmaking and, indirectly, to the institutional and macrosociological contexts of the news media" (ibid: vii).

A useful example of this approach applied to journalistic material is his earlier work on racism in the press (1991). Following transnational research on the negative representations and stereotyping of racial minorities, van Dijk highlighted the institutional bias against ethnic minority leaders and workers, with minority journalists often discriminated against in professional environments (1991:X).

He addressed a range of theoretically informed discussions on key areas in his discourse analytic framework of the press: social cognition and the ideological processes and contexts of cognitive strategies; interrogations of structural and strategical processes in news production; the public reproduction of racism, beliefs and attitudes in the production and consumption of news; and the complexities of elite racism impacting upon journalistic practice and content. This socio-cognitive approach studied multiple dimensions of newspaper discourse and practice: headlines; subjects and topics; news schemata, argumentation and editorials; quotations and sources; meanings and ideologies; style and rhetoric; and the reproduction of news on ethnic affairs. This research was methodologically significant at the time due to the interdisciplinary theoretical scope and its synergy of quantitative (content analysis) and qualitative (C/DA) approaches:

Another popular approach in critical media research, which again developed from its roots in $\mathrm{CL}$, is Fairclough's $(1995,1998,2001,2003)$ three layered model of CDA. This framework transcended "the division between work inspired by social theory which tends not to analyse texts, and work which focuses upon the language of texts but tends not to engage with social theoretical issues" (2003:2-3). Fairclough's approach includes "interdiscursive analysis, that is, seeing texts in terms of the different discourses, genres and styles they draw upon and articulate together" (Fairclough, 2003:3). This enables a critical outlook on "the relatively durable structuring of language which is itself one element of the relatively durable structuring and networking of social practices" (ibid:3).

The first layer of Fairclough's model is concerned with textual analysis. This is more than linguistic or grammatical analysis of texts; like $\mathrm{CL}$ it concerns the ideological role of language as a social product. As Paul Simpson explains, language is used by powerful groups to reinforce dominant ideologies and therefore needs to be studied as a site of ideological struggle (1993). Hence, the second layer of analysis is discursive practice. In terms of news discourse and journalism, textual features are all seen to occur through decision making processes in their cultural and professional contexts. Journalists and news organisations are wrapped up in cultural practices of time and place as well as their employers having their own editorial interests and socio-economic agendas to fulfil. Attention to discursive practice means that processes of textual production and consumption are scrutinised. Discursive practices can account for the ways in which "authors of texts draw on already existing discourses and genres to create a text and ... how receivers of texts also apply available discourses and genres in the consumption and interpretation of ... texts" (Phillips and Jorgenson, 2002:69). This has been particularly important in Kelsey's work on journalism, mythology, memory and discourses of national 
narration (Kelsey, 2015c). These elements reflect what Blommaert refers to in systems of reproduction, reception and remembering, which affect the way that texts are produced and consumed since socio-historical and cultural mechanisms form discourses and produce meaning (1999:5-6).

In Analysing Newspapers (2007) Richardson provides a rigorous example of Fairclough's model applied in journalism studies. In terms of discursive practice, he argues that journalists are workers who are pressured and obliged to respond to editorial, professional and managerial pressures and constraints on their content. Richardson also discusses the issue of objectivity (2007:86), where journalists reporting opinion must do so by reporting via sources and the views of people other than themselves. However, when sources are used to legitimise viewpoints and demonstrate objective reporting, issues regarding news access arise (Hall et al., 1978). Therefore, it is not the case that journalists are conspiratorially committed to elite sources or determined to reproduce dominant ideologies. Neither is it the case that a limited range of sources always dictates who speaks in the media. Rather, as Richardson points out, journalists need to use authoritative sources in order to protect themselves from criticism and appear to be objective.

Richardson (2007) continues to explore other levels of discursive practice at which processes of news production and consumption explain the dynamics of newspaper stories in relation to their readerships, editorial values and social context. In attempts to make sense of contradiction and ideological context in news stories, Kelsey has adopted aspects of this approach to CDA to examine the "paradoxical persuasions" of discourse (Kelsey, 2015b; Kelsey, 2015c). The "messiness" and inconsistencies of news demands a thorough cultural and political understanding of the social contexts in which the press operates. For example, Kelsey (2015b) analysed right wing newspapers during the London rights to show how the ideological consistencies operating beyond the foreground and immediacy of individual news stories override the appearance of discursive contradiction across longitudinal contexts.

These micro-macro complexities of discursive practice take us to the third level of Fairclough's model. Fairclough's third level of analysis is concerned with social practice. This level expands beyond media texts and examines some the wider social contexts of which the discourse is a product of and/or responding to. This is often the level where CDA takes an explicit normative or political position in response to a problem, dominant ideology or exploitative social relations (Richardson, 2007). It is here, in the overlapping ground between discursive and social practices, which supplement each other through the production and consumption of news texts, where CDA begins to oscillate between its linguistic roots and connections to social, cultural and critical theoretical analysis. This addresses broader questions regarding the social and political role of journalism; considering anything from what news says about the society in which it is produced to the impact it has on the (reproductive) social relations that it is a part of (Richardson, 2007).

In Kelsey's research $(2012 ; 2014 ; 2015 c ; 2015 d)$ the analytical toolkits and insights of CDA covered so far have been synergised with cultural theory to analyse mythology and ideology in journalistic storytelling. Discourse Mythological Analysis (DMA) is a model that developed over time through two main objectives: to use the tools of CDA to analyse discursive constructions of mythology in news stories; to show how myth theory can demonstrate cultural, semiotic, archetypal and ideological functions of news discourse and journalistic storytelling (Barthes, 1993; Lule, 2001; Kelsey, 2015c). Analyses of news as a form of mythological storytelling are not uncommon in journalism studies (Lule 2001; O'Donnell 2003; Bird and Dardenne 2008). Lule argues that mythological storytelling justifies ideological standpoints: "Myth celebrates dominant beliefs and values. Myth degrades and demeans other beliefs that do not align with those of the storyteller" (ibid, 184). This selective process is a highly 
politicised negotiation of discursive practices: "The diachronic and synchronic formations of mythology might articulate simple messages but they are complex processes that often provide sophisticated manipulations of popular stories, memories and identities" (Kelsey 2015c:187). Journalists are storytellers (or mythmakers) in contemporary societies: "Like myth tellers from every age, journalists can draw from the rich treasure trove of archetypal stories and make sense of the world" (Lule 2001:18). Equally, audiences often rely on the same archetypal conventions and familiar cultural mythologies to understand the stories they are told (Kelsey, 2015c; Kelsey, 2015d).

DMA combined Wodak's discourse-historical approach (Reisigl and Wodak, 2009) and Fairclough's (1995) three layered model to analyse the historical and social contexts of language, ideology and mythology. Wodak's approach examines the historical meanings, complexities, contradictions and ideological implications of words, phrases and stories in diachronic and synchronic contexts. In developing the DMA model Kelsey provided a detailed breakdown of differences between mythology, ideology and discourse; showing how discourse constructs myth, which carries ideology, yet ideology also informs discourse in the construction of mythology (Kelsey 2014, 2015c, 2015d). Since systematic frameworks for analysing the detailed discursive constructions of myth have been largely absent in myth theory (Flood, 2002), DMA offers a systematic toolkit by drawing on CDA to apply cultural theories of mythology to news texts. It is important to understand how myth "arises from the intricate, highly variable relationship between claims to validity, discursive construction, ideological marking, and reception of the account by a particular audience in a particular historical context" (Flood 2002). DMA not only helps to fill this necessity that Flood points to, but it also provides a distinct synergy between journalism studies and discourse studies as research disciplines: "DMA [is] a systematic analytical framework that can be adopted to investigate discursive constructions and ideological operations of mythology in journalistic storytelling" (Kelsey 2015c:3).

Through this summary of developments in CDA since $\mathrm{CL}$ we can see how this stage introduced significant expansions in critical media research. An impressive range of transnational and interdisciplinary approaches have seen CDA expand and developed into a cross-cultural field of research (Kuo and Nakamura, 2005; Alvaro, 2015; Flowerdew and Leong, 2007, 2010; Hardt-Mautner, 1995; Way, 2015). These approaches have demonstrated how CDA can oscillate across cultures and contexts of power and language.

\section{Transnational developments in CDA and journalism studies}

The literature covered in this section shows how CDA has evolved transnationally to consider the discursive and journalistic dynamics that operate in processes of language translation, national and international environments, and other intercultural tensions of media and society. Kuo and Nakamura (2005) use CDA to analyse headlines, editorial choices (deletions and additions), linguistic variations, stylistic differences and thematic changes in translated Chinese versions of the same English language text. They argue that these translations are actually more transformations since the "differences found in the two Chinese texts are not arbitrary, but rather are ideologically motivated, that is, they reflect and construct the underlying opposed ideologies between the two [Chinese] newspapers" (2005:393).

Alvaro also adopted a "sociolinguistic view of China's English language media and its attempted penetration of the global language community" (2015:260). By adopting Kachru's Caliban dynamic as a metaphor, Alvaro examines how China disseminates ideological messages back to the 'colonisers' through a Sinocentric from of English language (ibid:260). Alvaro's earlier work adopted CDA to 
examine Chinese media discourses "in which a dissident social actor is represented in China's staterun English-language press" (2013: 289). Alvaro shows how Chinese media discourses use passive agent deletion, definition/re-definition, and the attribution of derogating qualities to dissidents in news stories. He argues that this serves the purpose of similar dynamics to an ideological square (van Dijk, 1998:267), since this media introduces ideological bias through representations of positiveSelf/negative-Other in the discourse on dissidents.

This international adoption of CDA applied to multiple journalistic genres is also reflected in Juuko's work on the Ugandan broadcast media's framing of environmental risk. Her analysis shows how media sources "reproduce the order of the hegemonic discourse, whereby, the wealthy elite are highly regarded while the poor ordinary people are marginalized" (Juuko, 2015:2). Whilst those marginalized voices occur in media coverage, "the situation is framed as a consequence of their activities, consequently 'blaming the victim', a strategy that usually serves to 'justify a perverse form of social action designed to change not society, but rather society's victim' (Melkote and Steeves 2001: 331)" (ibid: 2). Way's work has also adapted CDA to analyse the ideological tensions of broadcast media in coverage of Turkish-Cypriot conflicts (2015). By examining radio news broadcasts in the Turkish Republic of Northern Cyprus, Way shows how media coverage aggravated relations with the Republic of Cyprus during a period when explicit efforts had been made to improve relations between the two regions. Way argues that whilst broadcasters appeared to be applauding the election of profederation politicians and diplomatic efforts to resolve the conflict, closer attention to the language of radio news did not reflect a pro-solution discourse. Instead, the lexical and grammatical construction of radio news perpetuated the conflict by communicating "uncertainty, suspicion and even threat, in each case slightly differently, to support each station's associated ideologies and interests which are consistently anti-unity" (ibid:2). This ideological context was a result of close relationships between "news media and politics where a plurality of stations offer a range of viewpoints but all are connected to political parties and interests whose concerns are mostly that of self-interest" (ibid:2).

The news media's role in constructions of national identity and its ideological significance in policy discourses were also examined by Flowerdew and Leong (2007) in their analysis of Hong Kong's reform debate. Their analysis examines "the role of metaphors in the discursive construction of the notion of patriotism in postcolonial Hong Kong" (ibid:273). By analysing news reports and opinion pieces from two local newspapers covering the issue of patriotism they provide an insight to "the role of language in constructing the identity of a patriotic Chinese" (ibid:273). Furthermore, this analysis helps to provide a better "understanding of the politics and tensions between the local and the national under the unprecedented 'one country two systems' arrangement of postcolonial Hong Kong" (ibid:273).

Issues of patriotism and national identity in news media have seen CDA adopted in European contexts to examine cultural constructions and ideological tensions in the European Union (Kelsey, 2015d; Hardt-Mautner, 1995). Hardt-Mautner (1995) examined how the British press represented and responded to the challenges of European integration and EU policy-making processes. Her analysis showed that national stereotyping features significantly in the news coverage of France and Germany and data from the Sun newspaper was "used to illustrate strategies employed to make elite discourse more accessible to the lay reader" (ibid:177). Kelsey (2015d) has also shown how the British press and rhetoric of the UK Independence Party continue to play a significant role in media and public discourse around EU integration, membership and referendum debates.

The literature covered so far across two developmental stages of CDA has developed significantly since its initial foundations in $\mathrm{CL}$ and has become a transnational field of research. However, there are further cultural nuances and technological developments to account for, which are significant to CDA, 
in multimodal approaches to news discourse. Transnational scholarly efforts to introduce journalistic research to the field of CDA (and vice versa) have recently expanded through other frameworks concerned with the visual and technological developments of news media.

\section{Multimodal CDA and online news}

This section accounts for developments that have responded to the challenges of analysing multimodal discourse and, more recently, online news (Jones, 2004; Van Leeuven and Kress, 2011; van Leeuwen, 2004; Machin and Mayr, 2012; Bednarek and Caple, 2012; Caple, 2013; Kelsey, 2015a). The foundations of multimodal research are based on social semiotic theories (Barthes, 1993; Thibault, 1991) that have been commonly adopted in communication and language research (Halliday, 1994; van Leeuwen, 2004; Van Leeuven and Kress, 2011). In this conceptual and analytical approach, no single component of a multimodal formation functions in isolation at any single moment. Van Leeuven and Kress describe this as the study of "the material resources we use in multimodal communication, and the way we use these resources for purposes of communication and expression" (ibid: 109). Similarly, Bednarek and Caple's (2012) approach considered discourse as an incorporation of both language and image in their semiotic modes that are simultaneously operating in their uses across different news sources (including print, broadcast and online), to show how various discourse analytical approaches can be applied to these formats.

Caple argues that "multisemiotic storytelling" has developed through online news environments (2013) and the images of online news provide multifunctional purposes in the construction of a story and its interactive dynamic with the reader. The traditional news'paper' story displays its familiar features online combined with other multimedia and interactive elements that are becoming increasingly relevant to developing forms of participatory communicative practice and multimodal analysis: "[Online news stories] represent the institutional news media in the sense that they are usually produced by media professionals. However, the more significant change is that they are published along with user-generated genres that have become popular through social media..." (Caple, 2013: 83-84). Therefore, more expansive considerations of entire multisemiotic conventions provide the opportunity to see how stories stimulate particular readings, responses and debates that are significant to the communicative practices of news stories in their entirety. For example, Caple illustrates the significance of system networks and how to adopt metafunctional approaches to analysing news images (2013:58). Caple's work is important because, amongst other innovations in this theoretical and analytical progress (Knox, 2007, 2010), it shows how Halliday's framework of Systemic Functional Linguistics (SFL) can be adapted and applied through multisemiotic approaches to online news. Knox, for example, made significant advances in SFL for semiotic research by analysing the function of thumbnail images in newsbites and hard-news stories to show how they have become part of significant discursive practices in contemporary news production and consumption. Knox's work is important because he identifies newsbites (headline-plus-lead-hyperlink) on newspaper website homepages as complex signs containing hyper visual elements that attract and stimulate readers in different ways (also see Caple, 2013; Bednarek and Caple, 2012). Knox argues that a newsbites operate as "independent texts in their own unique contextual environment to construe actors and events according to the institutional goals and ideologies of the newspaper" (2007:26). This is particularly relevant to my case study below regarding the Mail Online.

Other adaptions of SFL have seen Halliday's work merged with Gestalt theories of perception psychology (Engrebretsen 2012) to analyse the "cohesion/tension nexus in multimodal cohesive relations" (Caple, 2013:14). Whilst the move towards discursive-psychological frameworks can take 
this discussion of CDA into complex territory beyond the scope of this chapter, it is significant that recent work by Wetherell has also argued that approaches in discourse research are compatible with affect theory (Wetherell, 2012; Kelsey, 2015a). This is important given that online news has become an increasingly interactive and participatory process between news stories and its readers with meanings and discursive contributions that complicate the traditional, more linear, process of news production and audience consumption. We can now access significant insights into what happens amongst groups and individuals when they come into contact with news stories.

Storytelling is highly emotive. As Wahl-Jorgensen argues, strategic rituals of emotionality in journalism manifest themselves "in the overwhelming use of anecdotal leads, personalised story-telling and expressions of affect. However, journalists never discuss their own emotions but instead 'outsource' emotional labour by describing the emotions of others, and drawing on sources to discuss their emotions" (2013;129). It is also the case that ideologies influence emotions and emotions in turn influence ideologies (Kelsey 2015a), which inform discursive expressions, exchanges and events. Wetherell refers to these endless cycles as affective-discursive loops (2012:53). As Wetherell argues, discourse often "makes affect powerful, makes it radical and provides the means to make affect travel" (ibid: 19). In its entirety, human affect and emotion is "inextricably linked with meaning-making and with the semiotic (broadly defined) and the discursive" (Wetherell, 2012:20). The evolving dynamics of online news show us how discursive practices are intricately bound up in processes of affecting and being affected by social and technological changes in media cultures. Since Wetherell (2012) recently introduced the notion of affective practice to discourse analytical vocabulary, Kelsey (2015a) incorporated this through a multimodal framework of CDA for online news, which informs the case study below.

\section{Multimodal case study: The Mail Online}

Since current analyses of journalistic texts are so often embedded within the context of online media, CDA should continually find ways of understanding the media convergence factors and multimodal mechanisms involved in news production, consumption and participation. This analysis focuses on the commercial interests and discursive practices of the Mail Online through material from one news article: the embedded video of an assault that took place on a beach in Connecticut; the news text from the Mail Online; and the reader comments below the article, which provide insights to audience comprehension and responses that were less accessible for CDA research prior to online news. ${ }^{i}$

Embedded videos have become a significant feature of digital journalism. They provide a significant stylistic feature of the Mail Online that has a highly successful business model as the most popular newspaper website in the world. What is significant about the Mail Online's success is the exacerbation of commercial and business interests that have increasingly impacted upon news content. As Richardson explains, "advertisers will not subsidise a news producer without an audience. And this pushes journalism towards increasing light, entertaining copy at the expense of more weighty examinations or more expensive long-term investigative reporting" (2007:78-79). Online news that seeks to update its homepage regularly across a 24 hour period seeks as much copy as possible to reproduce as quickly as possible. Hence, the Mail Online has been described by its editor, Martin Clarke as "journalism crack". The Guardian followed up on this:

"Journalism crack" is an apt metaphor for Mail Online's user experience and the way rival news websites have adopted its reader retention methods - the much derided but utterly addictive 
"sidebar of shame", seemingly never-ending front page, and stories so stuffed with pictures and video they are more vertical gallery than text-based article.i

Mail Online content is often lifted from other social media platforms and reproduced for its own audience. This is a practice that Clarke has defended by claiming that the Mail Online improves stories with "new facts, graphics, pictures, or video", despite the fact that it has been accused of increasingly poor journalistic practice in a lack of attribution to sources of material it uses.iii

Ironically, the Mail Online is not only competing with other newspapers for audiences to sell to advertisers, but it has to compete with the same social networks that it relies upon for its dissemination and sharing of content. Mail Online owner, Viscount Rothermere sees the likes of Twitter and Facebook as "frenemies", stating: "They are going to compete for advertising dollars, that's undoubtedly the truth, but they are a huge source of traffic for us. We are the most-shared site on Facebook in the UK and growing to become the same in the US" (2013). Rothermere is quite frank about the blending of entrepreneurial and editorial interests that drive the Mail Online's commercial success: "I'm very fortunate to come from a family where we believe in editorial and creativity - that's a major thing in our organisation. ... And because our family are entrepreneurs, we sympathise and empathise with entrepreneurial spirit, and that has allowed us to diversify our business internationally" (ibid). This blend of editorial and business interests delivered through its online format have turned the Mail Online's journalistic practice into a convergence exercise of multimedia platforms that can be used to constantly engage its readers with new content and sell its audiences to advertisers. The following multimodal analysis sheds some light on the journalistic and user generated content involved in the production, consumption and participatory features of an online news story.

\section{Gender ideology and online news: The Connecticut beach fight}

When 17-year-old Austin Haughwout used his drone to film aerial shots of Hammonasset Beach in Connecticut, 23-year-old Andrea Mears accused him of photographing people on the beach. Mears physically attacked Haughwout, called the police and accused him of assault. During the attack Haughwout used his phone to record the incident without Mears' knowledge. The video was used by the police who arrested Mears for assault. During the video of this attack we see Haughwout burdened with the voyeur stereotype, where he is accused of "perving" on people. The video shows Mears physically beating Haughwout whilst screaming threats and accusations at him for being a pervert. The recording then featured in news stories online, where Mears was subjected to sexist abuse. From a critical perspective, despite Mears' guilt, we should still think about the ethical values of the news story and the video's circulation and reproduction: there is an argument to make regarding an invasion of Mears' privacy once the video had rightly served its purpose in proving the roles of victim and perpetrator in this case. Nonetheless, the video was not just embedded in the story, it was the story. ${ }^{\text {iv }}$

It is significant that this video is not journalistic - it is not even citizen journalism. It has appeared online in many contexts other than this news story. Even when the video is embedded in a news story it does not become a journalistic piece per se. However, it becomes a significant part of journalistic storytelling and it does influence how a story can (or cannot) be told; when an audience can see the events unfolding through this medium it does to some extent limit the creative or reproductive agency of the storyteller compared to a traditional print format. The video does not carry the same mystique as an "anonymous" source or "eyewitness" that we commonly see journalists using to legitimise an account of events in a story. Neither does it rely on the translation of a journalistic soundbite, nor is it 
used to infer the subjective interpretation of what a source supposedly said. Nonetheless, despite these factors, the storyteller is not left redundant or passive. As we see below, the discursive construction of the story in which the video is embedded can still influence its contextualisation and what the story is about. As we see below, its reproduction and convergence from one online media platform into a journalistic context, which stimulates responses from readers, is still an ideologically influenced practice.

The newsbite on the Mail Online video homepage reads: "Crazed woman assaults man for flying drone on beach". The headline on the article page reads: "Moment angry woman assaulted a man for flying his drone on the beach and accused him of being a 'pervert'". "Crazed" implies madness and insanity, which lacks the same sense of agency that "angry" implies on Mears' part. We can only speculate about this editorial decision. But following Knox's $(2007,2010)$ point earlier, thumbnails and newsbites serve a purpose in attracting readers to click on stories, which in turn produces advertising revenue. Either way, the article is in no way sympathetic to Mears' position or how she was affected by Haughwout's agency. The problem here lies in the fact that this became a gendered communicative process; the user comments (below) make sexist remarks about Mears whilst expressing broader social commentary on perceptions of gender relations. Rather than contesting or condemning the mistake of Mears as an individual, some readers recontextualised this attack (ideologically) as an example of gender inequality, identifying men as the victims of common sexism, legal injustice and moral double standards.

Since the evidence in this video and the drone footage checked by the police demonstrate Haughwout's innocence, the article is able to tell a clear story that condemns the actions of Mears without leaving any remaining suspicion around Haughwout. Whilst it is not wrong to state Haughwout's innocence in this event, a broader contextual problem lies in the lack of attention or empathy given to concerns about privacy, intrusion and public anxieties around drone technologies. In another context, this could be a story about the growing social tensions and confusions caused by surveillance cultures and digital technologies (Kelsey, 2015a: 16-17). But through the dichotomy of a "victim versus perpetrator" story, in which a "crazed" or "angry" woman attacks a young man, these other complexities and attention to social anxieties are interruptive details, which might compromise the spectacle that stimulates those responses in the user comments. Nonetheless, the suppression of empathy here is significant given the multiple public discourses and anxieties around surveillance technologies, privacy, crime, the internet and the affect that these concerns have on peoples' feelings, thoughts, perceptions and actions.

In the "best rated" comments under this article, we see the interdiscursive melee that this story stimulated, and the gender ideology that was central to that stimulation. Some of the "best rated" were brief, abusive and personal attacks on Mears' physical appearance: "She's lucky he didn't beat her fat ass on camera"; "She needs to get a mirror. Nobody would want to take pictures of her". But some of the most popular "best rated" comments speculated about the punishment Mears would (or would not) receive as a woman. C1 and C2 are the top rated comments (with replies indented):

C1: Clever kid for filming it. Unfortunately, without the video, the police would undoubtedly have sided with her and he would have left in handcuffs. She'll probably get a slap on the wrist now and be on her merry way.

R1: True. Any woman that will beat a man like that will also lie and blame him if she can get away with it. 
R2: Imagine it the other way round. 26-year-old man attacks 16-year-old girl and rips off her shirt and unzips her pants. He's looking at serious jail time, she is looking at an inconvenient fine.

C2: She belongs in jail. Equal punishment for women for equal crime.

R1: It is not an equal crime, if you had been paying attention in school you would know that a male body has a much greater muscle mass and therefore a great advantage physically over a female. This is no reason for women not to have equal rights however.

R2: [R1], you are spot on. Not that we are excusing this behaviour at all from this "lady". Her behaviour is disgusting, and she should get punished. I hope that she grows up and changes from this incident. [R1], you are right though, if a man was to attack a woman this way she would be a lot worse off. Again, no excuse on the woman's behalf anyway. Oh, and R2...you're living in a fantasy world if you think most men even go to jail for assaulting women. They don't.

R3: [R1], you're talking rubbish! Just because the female may be smaller does not make any difference at all. There are plenty of women bigger and more powerful than men.

R5: Don't waste your time [R3], women only want equal rights when it suits them.

R6: He was doing what that woman accused him of. She jumped the gun without getting her facts straight and that's why she deserves to go to jail. I bet if it was the other way around you offer to burn him at the stake yourselves.

In this user-generated content we see feelings (stimulated by the story) of outrage and injustice expressed through discourses of (in)equality, double standards, hypocrisy, domestic violence, law \& order, and morality. There are simultaneous dynamics operating between the dialogical contexts of readers interpreting this story, the affective practices that stimulate their emotive responses to the article, and the ideological tensions of the debate. There are interdiscursive practices in the argument under $\mathrm{C} 2$, which reflect the dialogical formation of gender ideologies that respondents are carrying, expressing and opposing through the dialogue of this exchange. Both sides of the argument attempt to empathise with their perceptions of how society and the legal system deal with gender violence. We also see Haughwout praised for filming ("smart kid"), on the assumption that he would have been charged with assault otherwise.

As Jones (2004:22) points out, "what counts as context is not limited to the physical reality surrounding the text. Instead the focus is on the 'models' that people build up in their minds (and in their interaction) of the situation" (Jones, 2004:22). And as Wetherell (2014) argues: "Affective-discursive practices such as 'doing righteous indignation' or 'doing being the victim' are so salient and crucial in political life and yet are deeply methodical and mannered". This applies to multiple participants throughout this case from Mears' actions in the video to the perceptions of those attacking her in the comments. They all follow the narratives they have constructed in their contextual interpretations of an article that plays on the divisive dichotomies of gender ideology.

What is interesting about the replies (challenging C2) that stimulated the debate is their effort to address some complexity beyond the assertions of those users who see this as a clear example of prejudice against men. This interruption to their understanding of the story is unwelcome, even though the respondents clearly state that they do not condone Mears' behaviour and they even agree that she should be punished. The way in which many users (in addition to those examples) responded expresses a deeper feeling of resentment and injustice that does not allow for any compromise. 
Haughwout's victimhood and the Mail's contextualisation of the story are used to justify their belief that men are subjected to injustice and unfair treatment in society.

\section{Conclusion}

This chapter has provided an overview of qualitative approaches to CDA in journalism studies. By recapping the relevance of $\mathrm{CL}$ in critical media research we can see how it has informed the theoretical and analytical roots of CDA since then. Furthermore, this chapter has accounted for multimodal approaches that are more applicable and dynamic in application to online news, which provides CDA with a new set of challenges compared to its focus on print and broadcast journalism in the past. A multimodal case study synergised approaches from across the chapter through a brief analysis that demonstrated the multimodal developments of CDA. The technological progressions of online news have exacerbated previous concerns about the commercial interests of news production and its impact upon journalistic content. The media convergence factors involved in the production, dissemination, consumption and participation processes of online news illustrate the multimodal dimensions that CDA needs to continually adapt and account for across transnational contexts. Researchers must continue to develop innovative approaches in CDA if the field is to keep up with these technological and cultural advances in journalism. 


\section{Bibliography}

Alvaro, J. (2015) Analysing China's English-language media. World Englishes, 34: 260-277. DOI: 10.1111/weng.12137

Baker, P. and McEnery, T. (eds) (2015) Corpora and Discourse: Integrating Discourse and Corpora. London: Palgrave.

Baker, P., Gabrielatos C., KhosraviNik, M., Krzyzanowski, M., McEnery, T. \& Wodak, R. (2008) A useful methodological synergy? Combining critical discourse analysis and corpus linguistics to examine discourses of refugees and asylum seekers in the UK press. Discourse \& Society, 19(3), 273-305.

Barthes, R. (1993) Mythologies. London: Vintage

Bednarek, M. and Caple, H. (2012) News Discourse. London: Cintinuum

Bell A (1991) The Language of News Media. Oxford: Blackwell.

Bird, S. E. and Dardenne, R. W. (1998) 'Myth Chronicle and Story: Exploring the narrative qualities of news.' In Carey, J. W. (Ed.) Media, myths and narratives (67-87) Beverley Hills, CA: Sage

Blommaert, J. (1999) 'The debate is open' in Blommaert, J. (ed) Language Ideological Debates New York: Mouton de Gruyter

Caple, H. (2013) Photojournalism: A Social Semiotic Approach. London: Palgrave

Engebretsen, M. (2012), 'Balancing cohesion and tension in multimodal rhetoric. An interdisciplinary approach to the study of semiotic complexity', Learning, Media and Technology, 37, 1-18

Fairclough, N. (1995). Critical discourse analysis: the critical study of language. Essex: Longman.

Fairclough, N. (2003) Analysing Discourse: Textual analysis for social research London: Routledge

Flowerdew J and Leong S (2007) Metaphors in the discursive construction of patriotism: The case of Hong Kong's constitutional reform debate. Discourse \& Society. 18(3): 273-294.

Flowerdew, J. and Leong, S. 2010. Presumed meaning in the discursive construction of socio-political and cultural identity. Journal of Pragmatics. 42(8): 2240-2252

Fowler, R., Hodge, B., Kress, G. and Trew, T. (1979) Language and Control. London: Routledge and Kegan Paul

Fowler, R. (1991). Language in the News: Discourse and Ideology in the Press. London: Routledge

Gabrielatos, C. \& Baker, P. (2008) Fleeing, sneaking, flooding: A corpus analysis of discursive constructions of refugees and asylum seekers in the UK Press 1996-2005.Journal of English Linguistics, 36(1), 5-38.

Hall, S. et al. (1978) Policing the Crisis: Mugging, the State, and Law and Order London: Macmillan

Halliday, M. (1978) Language as a Social Semiotic: Social Interpretation of Language and Meaning. London: Hodder Arnold

Hardt-Mautner G (1995) How does one become a good European? The British press and European integration. Discourse \& Society 6(2): 177-205.Hodge, R. and Kress, G. (1993) Language as Ideology. 2nd edn. London: Routledge. 
Jones, R. (2004). 'The problem of context in computer-mediated communication', in Levine, T. and Scollon, R. (eds.) Discourse and technology: multimodal discourse analysis. Georgetown University Press: Washington, 22-33

Juuko, M. (2015) Framing environmental risk in the broadcast media in Uganda. Journalism and Discourse Studies. 1(1) 1-17.

Kelsey, D. (2012a) 'Pound for Pound Champions: The Myth of the Blitz Spirit in British Newspaper Discourses of the City and Economy after the July 7th Bombings'. Critical Discourse Studies 9(3): 285299.

Kelsey, D. (2014) 'The Myth of the City Trickster: Storytelling, Bankers and Ideology in the Mail Online'. Political Ideologies 19(3): 307-330. Doi: 10.1080/13569317.2014.951147

Kelsey, D. (2015a) 'Discourse, affect and surveillance: gender conflict in the omniopticon'. Journalism and Discourse Studies, 1(2): http://www.jdsjournal.net/uploads/2/3/6/4/23642404/darrenkelseyjdsjournal-vol1-issue2.pdf

Kelsey, D. (2015b) 'Defining the sick society: Discourses of class and morality in British, right wing newspapers during the 2011 England riots'. Journal of Capital \& Class, 39(2)

Kelsey, D. (2015c) Media, Myth and Terrorism: A discourse-mythological analysis of the 'Blitz Spirit' in British Newspaper Responses to the July 7th Bombings. London: Palgrave Macmillan.

Kelsey, D. (2015d) Hero Mythology and Right-Wing Populism. Journalism Studies, DOI: 10.1080/1461670X.2015.1023571

Knox, J. (2007). Visual-verbal communication on online newspaper home pages. Visual Communication, 6(1), 19-53.

Knox, J. (2010). Online newspapers: Evolving genres, evolving theory. In C. Coffin, T. Lillis, \& K. O'Halloran (Eds.), Applied linguistics methods: A reader (33-51). London: Routledge.

Kress, G. (1983) Linguistic processes and the mediation of 'reality': The politics of newspaper language. International Journal of the Sociology of Language. 40: 43-57.

Kuo SH and Nakamura M (2005) Translation or transformation? A case study of language and ideology in the Taiwanese press. Discourse \& Society. 16(3) 393-417

Lule, J. (2001). Daily news, eternal stories: the mythological role of journalism. New York: Guilford Press.

Machin, D. and Mayr, A. (2012). How to do critical discourse analysis: a multimodal introduction. London: Sage

O'Donnell, M. (2003). Preposterous Trickster: myth, news, the law and John Marsden. Media Arts Law Review, 8 (4).

O'Halloran, K. (in press) Multimodal Analysis and Digital Technology. In Baldry, Anthony, Montagna, Elena, (eds.) Interdisciplinary Approaches to Multimodality: Theory and Practice. Readings in Intersemiosis and Multimedia. Palladino: Campobas

Philo, G. (2007) Can Discourse Analysis Successfully Explain the Content of Media and Journalistic Practice? Journalism Studies, 8(2), 175-196. 
Richardson, J. (2007) Analysing Newspapers: An Approach from Critical Discourse Analysis. Basingstoke: Palgrave Macmillan.

Reisigl, M., and Wodak, R. (2009) The discourse-historical approach (DHA). In R. Wodak \& M. Meyer (Eds.), Methods of critical discourse analysis (2nd rev. ed., 87-121). London, England: Sage.

Simpson, P. (1993) Language, ideology and point of view. London: Routledge.

Thibault, P. (1991) La langue enmouvement: simplification, régularisation, restructuration. LINX (Linguistique-Paris X, Nanterre) 25: 79-92.

Trew, T. (1979) 'What the papers say': linguistic variation and ideological difference. In Fowler, R., Hodge, B., Kress, G. and Trew, T. (eds.) Language and Control. London: Routledge and Kegan Paul

van Dijk, T. (1988a) News as Discourse. New Jersey: Lawrence Erlbaum Associates

van Dijk, T. (1988b) News Analysis. New Jersey: Lawrence Erlbaum Associates

van Dijk, T. (1991) Racism and the Press. London: Routledge

van Dijk, T. (1998) Ideology: A multidisciplinary approach. London: Sage.

van Dijk, T. (2001) 'Critical Discourse Analysis'. In Schiffrin, D. Tannen, D. and Hamilton, H. (eds.) The Handbook of Discourse Analysis. 352-371. Oxford: Blackwell

van Leeuwen, T. (2004) 'Ten reasons why linguists should pay attention to visual communication', in Levine, T. and Scollon, R. (eds.) Discourse and technology: multimodal discourse analysis, Georgetown University Press: Washington, 7-19

Van Leeuven, T. and Kress, G. (2011) 'Discourse Semiotics'. In van Dijk, T. (Ed.) Discourse Studies: A Multidisciplinary Introduction. 107-125

Wetherell, M. (2012) Affect and emotion: a new social science understanding. London: Sage.

Way, L. (2015) 'A fly in the ointment: How Turkish Cypriot radio news aggravates relations with the Republic of Cyprus'. Journalism and Discourse Studies. 1(1) 1-16

\footnotetext{
' http://www.dailymail.co.uk/news/article-2652262/Thats-little-pervert-Bizarre-moment-crazed-womanassaults-man-flying-drone-beach.html

in http://www.theguardian.com/media/2013/sep/01/martin-clarke-mediaguardian-100-2013

iii https://www.themediabriefing.com/article/mail-online-biggest-news-site

iv I have argued that surveillance cultures operate as affective practices since they regulate behaviour beyond merely human emotions; they influence our agency, actions and perceptions of spaces around us, through both semiotic processes and embodied meaning-making. For an extended analysis of this case beyond the journalistic focus in this chapter, and with further attention to surveillance theory in CDA, see Kelsey (2015a): http://www.jdsjournal.net/uploads/2/3/6/4/23642404/darrenkelsey-jdsjournal-vol1-issue2.pdf
} 